NBSIR 83-2684

A Review of Compartment Fire
Models

U.S. DEPARTMENT OF COMMERCE

National Bureau of Standards

National Engineering Laboratory

Center for Fire Research

Washington, DC 20234

April 1983

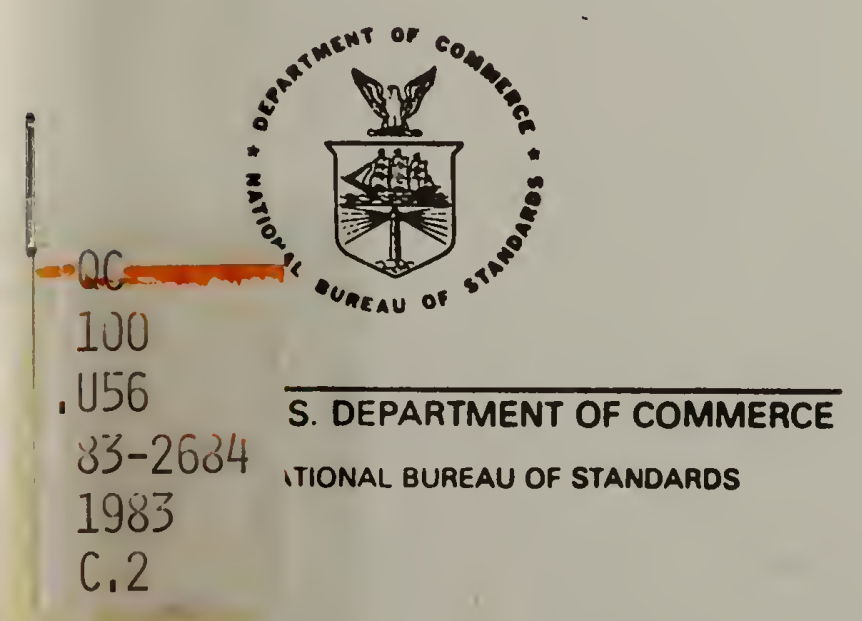


NBSIR 83-2684

\section{A REVIEW OF COMPARTMENT FIRE MODELS}

Walter W. Jones

U.S. DEPARTMENT OF COMMERCE

National Bureau of Standards

National Engineering Laboratory

Center for Fire Research

Washington, DC 20234

April 1983

U.S. DEPARTMENT OF COMMERCE, Malcolm Baldrige, Secrotany NATIONAL BUREAU OF STANDARDS. Emeot Ambler. Director 


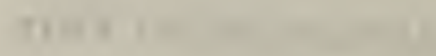
.

10

$\cdot$

\section{,} $\cdot$

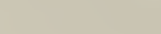

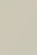

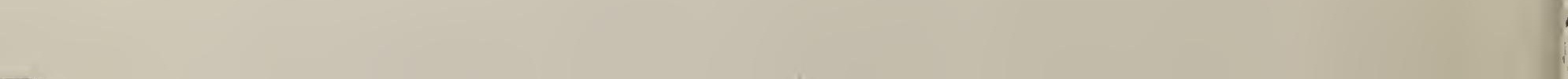
.

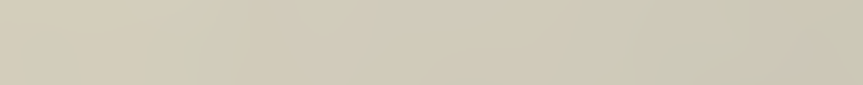
(20)

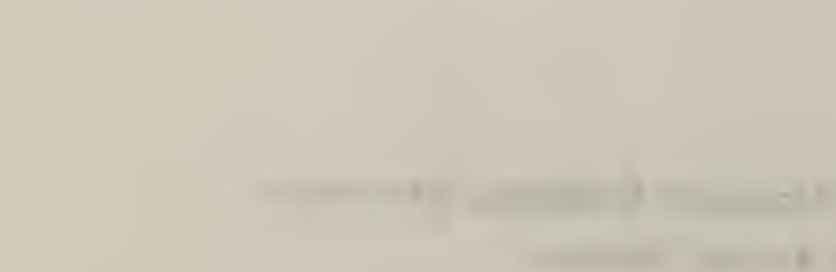


TABLE OF CONTENTS

Page

1. INTRODUCTION................................... 1

2. THE GOVERNING EQUATIONS............................ 2

2.1 Form and Special Assumptions...................... 4

2.2 Equations..................................... 5

3. RADIATIVE AND CONVECTIVE LOSS AND GAIN................ 8

3.1 Radlattve Loss and Gain........................... 9

3.2 Implementation of Radiation Formulae................ 13

3.3 Convect ton.................................... 14

4. ENTHALPY AND MASS FLUX............................ 15

4.1 Plumes........................................ 16

4.2 Door Jets and Mixing........................... 17

4.3 Spectal Cases and Selection Tables.................. 20

5. SUBSIDIARY EQUATIONS............................ 21

5.1 Fire Source.................................... 21

5.2 Radiation Between Object $8 \ldots \ldots \ldots \ldots \ldots \ldots \ldots \ldots \ldots \ldots \ldots \ldots \ldots \ldots . . \ldots 25$

5.3 Conduct lon................................... 25

6. CONCLUSIONS..................................... 27

7. REFERENCES..................................... 27

Appendix A - Nomenclature..............................

Appendix B - Summary of the Models......................... 


\section{FIGURE CAPTIONS}

Figure 1. Geometry used in calculating the radlative transfer. The box is a spectal case of the general geometry used in ref. [17].

Figure 2. Schematic of the dichotomy used in all of the zone models.

F1gure 3. Selection rules for determining the direction of flow driven solely by buoyancy.

Figure 4. The four flow regimes considered in the single compartment flow models. The external region is assumed to be ambient.

Figure 5. One possible configuration of the neutral plane height (N) and the lower layer/upper layer discontinuity $\left(z_{\ell}\right)$. Also indicated in the $f$ igure is the notation used for vent specification $\left(B, H_{\ell}, H_{U}\right)$.

F1gure 6. The nine possible flow conditions. The "SA $1 f$ " notation is taken from Tanaka [18]. Compartment two 18 assumed to be amblent. The selection rules determine which flow formula is to be used to calculate the vent flow. 


\section{INTRODUCTION}

The purpose of this review is to bring together the various fire models which have been constructed over the years, in the hope of defining a general framework for further research in the field of fire modeling. In this context we will attempt to formulate each model (or numerical implementation) in terms of similar variables. No attempt will be made to justify or rederive each facet of each model. Rather we will elucidate the assumptions and enumerate the equations behind each mode1. References (1-16, 18-19) describe the models in detail, and Appendix B summarizes them.

The specific topic is the one-room model. All of the physics and chemistry which has been developed for a one-room model will be discussed. The model is assumed to be embedded in a world of uniform temperature $T_{a}$ and reference pressure $P_{a} \cdot$ (The outside wall is at $T_{e}$ which may not be the same as $T_{a}$ ) A more general treatment is possible, but in discussing doorway phenomena in particular, the problem of multiroom connections would simply cloud the issue of what physics is actually present in each of the models.

The discussion is broken down into the basic conservation equations, the source and sink terms for these equations, and then the subsidiary equations which deal with interaction of various objects in a single compartment fire. The governing equations are divided in this manner to facilitate the development of a model (and numerical code) which will be modular in scope as well as general in application. With such a model we would hope that we can test various fire, fire spread, and entrainment models.

The notation used is detalled in Appendix A. In addition to being consistent within the monograph, the symbols chosen were those most commonly used by the various authors. In other cases, for example where several symbols were used, it is hoped that a judictous cholce will make the text clearer. For symbols which are used only within one section, 
or where the usage differs slightly, these symbols are defined in the text. Appendix B contains a bibllography of the models discussed in this report. Within the text they are referred to as (NBS-I, NBS-II, BRI, Harvard, Cal Tech and Dayton). This indicates the general geographlc origln of the models. There are several references for each one, usually generated as one aspect or another is studied in detall. Rather than attempting to reference each model completely at each occurrence in the text, they will be referred to by the above generic names, and for the interested reader a more detalled explanation is provided in Appendix B.

\section{THE GOVERNING EQUATIONS}

The basic equations describe mass, momentum and energy transfer from point to point in a fire related environment. These equations will be formulated in a way which describes the flow from one volume to another. Thus they are couched in the integral formulation of "control volumes". These control volumes will be of sufficlent size that we will require only a few to describe any system of interest. The cholce is based on the premise that the detalls which occur within such a volume do not concern us (at present), but their mutual interaction does.

In considering dynamic systems, it is necessary to solve a problem self-consistently in terms of conservation of mass, energy and momentum. If such is not done, then some of the dynamics may be obscured or even lost. In particular, discussion of movement of the zone interfaces should be self-consistent.

By appropriate mantpulation the conservation equations for mass and energy can be transformed into the form

$$
\begin{aligned}
& \frac{d m}{d t}=\sum_{i} \dot{m}_{i} \\
& c_{p} m \frac{d T}{d t}-A_{d} Z \frac{d P}{d t}=\dot{Q}+\sum_{1} h_{i} \dot{m}_{1}
\end{aligned}
$$


and

$$
P=\rho R T
$$

where $\dot{Q}$ is the net energy input to the volume due to radiation (frum all sources), convection and conduction, and $h_{1}$ (the enthalpy of the $L^{\text {th }}$ ubject in the cuntrul volume) is relative to the initial temperature of the volume from which the mass parcel $\dot{m}_{i} \delta t$ came. The equation of state for an ideal gas is usually used for clusure of the system. More currectly it should be written

$$
P=P(\rho, T)
$$

especially fur applications tu fire problems which are nut ideal gas problems. Huwever, fur the case of an ideal gas, the derivations and discussions are simplified, and generalizations can be discussed later. The sign cunvection is that pusitive fluxes on the right hand side of an equation will increase the quantity being calculated on the left hand side, that is, transfer into a volume is indicated by a pusitive flux un the right-hand side.

The basic differences which arise amung the mudels can be discussed using these equations as a basis. In an alternative furm of the energy equation, written in terms of the internal energy (nut enthalpy) an explicit work term appears

P $\delta V$

in place of the time derivative of pressure in equation (2). If the energy equation is to be sulved in this form, then this work term should be carried explicitly.

Table I shows which of the zone models include, at least in principle, either the pressure derivative or the volume work term in their derivations but nune of these mudels retain this term in the energy equation. 
Table I

\begin{tabular}{lc} 
Model & Included \\
\cline { 2 - 2 } NBS-I & Yes \\
BRI & No \\
Harvard & No \\
Cal Tech & Yes \\
Dayton & No
\end{tabular}

The most important contribution to the pressure term $\left\{v \delta t \frac{d P}{d t} \mid\right.$ ext $\}$ is due to exothermic reactions and forced ventilation. This term arises, for example, when chemical energy release results in an increase in the volume occupied by the gas as well as the internal energy of the gas. If the gas were not allowed to expand, then the pressure in the compartment would increase. With the usual leaks present in rooms, the internal pressure change is essentially negligible and in general this term is small. However, it may be appropriate to retain this term since not all problems will necessarily allow such an approximation.

\subsection{Form and Special As sumptions}

The general form of the zone (control volume) model is to divide each compartment into two zones: an upper zone which contains a hot layer, and a lower layer which is often, but not always, constdered to be at ambient conditlons. There may exist one or more fires and plumes in a room and these can usually be considered to be part of the upper zone. Mass and energy transfer between the zones is provided by the plumes and mixing at vents as well as radiation between layers. This is true for all of the models and is possibly a deficlency since there is experimental evidence that shows mass flow can occur along walls and other boundaries. In general the plume, once created, simply transfers mass and energy from one zone to another. Another set of equations could be written for the plume, but as long as it is in quasi-steady state, considering it to be part of the upper zone is quite sufficient. 
Another way of looking at the plume is to consider it so small in mass, energy content and volume that it can be ignored except as a transfer mechanism. For some problems, however, the plume must be considered a separate zone along with the concomitant conservation equations.

Mass and convective enthalpy transfer to and from a layer can exist at an arbitrary number of ports, although only the BRI model allows direct vertical transfer for multi-level buildings. Finally, radiation and convection are allowed to and from walls, floors and cellings. The Harvard model includes detailed heat transfer to the fire source and other Internal objects as well.

The specific formulation for a single compartment will be discussed. It will be in a form which allows general connectivity to other compartments. Then a discussion of the physical phenomena is in order. These are the pieces which then become part of the general flow equations.

\subsection{Equations}

For a given compartment there exist three equations and four unknowns for each zone. There are several variations of these equations which have been used.

The general form of eqns. (1-3) together with the subsidiary equations

$$
H=z_{u}+z_{\ell}
$$

and

$$
\mathrm{P}_{\mathrm{u}}=\mathrm{P}_{\ell} \text { at the zone boundary }
$$

provide closure for the model. An Implicit assumption is that the cross section ( $A$ ) is known, and is usually assumed to be constant, $A \neq A(z)$, where $\mathrm{AZ}=\mathrm{V}$. The subscripts " $\mathrm{u}$ " and " $\ell$ " represent "upper" and "lower", respectively, whereas " $i$ " refers to openings to other zones, other compartments or external volumes. 
With the assumption of two zones per compartment, there exist two sets of equations (1-3), one for each layer. In some cases, of course, one zone may be infinitesimally small, such as the upper layer at $t=0$. Specifically there are four differential (1-2) and two algebraic equations (3), together with the two subsidiary equations (5-6) for each compartment. Substitutions can be made using the subsidlary equations which still leaves unknown the manner in which the other varlables will be found. For numerical purposes, as well as having common grounds for comparison of the models, we will write the equations in terms of

$$
m_{u}=Z_{u} A \rho_{u}, m_{\ell}=Z_{\ell} A \rho_{\ell}, V_{u}, V_{\ell}, T_{u}, T_{\ell}, P_{u} \text { and } P_{\ell}
$$

This yields six equations in elght unknowns,

$$
\begin{aligned}
& \frac{\mathrm{dm}}{\mathrm{dt}}=\sum_{1} \dot{\mathrm{m}}_{\mathrm{i}, \mathrm{u}} \\
& \frac{\mathrm{dm} \ell}{\mathrm{dt}}=\sum_{1} \dot{\mathrm{m}}_{1, \ell}
\end{aligned}
$$

$$
c_{p} m_{u} \frac{d T}{d t}=v_{u} \frac{d P}{d t}+\dot{Q}_{u}+\sum_{1} h_{1, u} \dot{m}_{1, u}
$$

$$
c_{p} m_{\ell} \frac{d T_{\ell}}{d t}=v_{\ell} \frac{d P_{\ell}}{d t}+\dot{Q}_{\ell}+\sum_{1} h_{1, \ell} \dot{m}_{1, \ell}
$$

$$
\begin{aligned}
& P_{u}=\rho_{u} R T_{u} \\
& P_{\ell}=\rho_{\ell} R T_{\ell}
\end{aligned}
$$

together with the subsidiary assumptions $\mathrm{P}_{\mathrm{u}}=\mathrm{P}_{\ell}$ at the interface between the zones and $v=v_{\ell}+v_{u}$. The set of equations can, and usually is, simplified somewhat. The pressure consists of a reference pressure at the floor and a hydrostatic term 


$$
P(Z)=\bar{P}(f l o o r)-\int_{0}^{Z} \rho g d Z \text {. }
$$

The hydrostatic term is considerably smaller than the reference pressure, $\overline{\mathrm{P}}(\mathrm{floor})$. Thus, change in pressure as a function of height is important only for calculating the helght of the neutral plane and the relative pressure between two vents, the latter being important for vent flow calculations. This simplifies the equations in the following manner

$$
P_{u}=\rho_{u} R T_{u} \simeq \rho_{\ell} R T_{\ell}=P_{\ell} \equiv P,
$$

which reduces by one the number of independent variables. It should be noted that the reference pressure $P=P_{r}=\bar{P}$ (floor) is not independent of time, so that the term $\mathrm{dP} / \mathrm{dt} \neq 0$. This ylelds, finally, five equations in five independent unknowns. The specific set differs for each of the models, but all of them can be recast into this form.

The exact form in which these equations are solved vartes from model to model. Nevertheless, they all have the same source terms; that is, the right-hand side of equations (7-11) will be similar for each model, with differences showing up in the number of terms and the exact formulation for each term.

If we lgnore, for the moment, the problem of enthalpy of formation, then the enthalpy transfer terms can be written as

$$
h_{j} \dot{m}_{j, 1}=\dot{m}_{j} c_{p}\left(T_{j}-T_{1}\right)
$$

where $T_{i}$ is the temperature of the layer which is being changed and $T_{j}$ is the temperature of the layer from which the gas is coming. With these assumptions, approximations and insertions, the four differential equations can be written as

$$
\frac{d}{d t} m_{u}=\dot{m}_{p}+\sum_{i} \dot{m}_{i, u}
$$




$$
\begin{aligned}
& \frac{d}{d t} m_{\ell}=-\dot{m}_{e}+\sum_{i} \dot{m}_{1, \ell} \\
& c_{p} m_{u} \frac{d}{d t} T_{u}=V_{u} \frac{d P}{d t}+\dot{Q}_{u}+\dot{m}_{f} c_{p}\left(T_{R}-T_{u}\right)+\dot{m}_{e} c_{p}\left(T_{\ell}-T_{u}\right) \\
&+\sum_{1} \dot{m}_{1} c_{p}\left(T_{i}-T_{u}\right) \\
& c_{p} m_{\ell} \frac{d}{d t} T_{\ell}=V_{\ell} \frac{d P}{d t}+\dot{Q}_{\ell}-\dot{m}_{e} c_{p}\left(T_{u}-T_{\ell}\right)+\sum_{i} \dot{m}_{1} c_{p}\left(T_{1}-T_{\ell}\right)
\end{aligned}
$$

where $\dot{Q}_{u}$ and $\dot{Q}_{2}$ are the heating, or couling, terms for the upper and lower layers, respectively. In the present discussion

$$
\dot{Q}_{u}=\dot{Q}_{R}+\dot{Q}_{C}+\dot{Q}_{f}+\dot{Q}_{0}
$$

and

$$
\dot{Q}_{\ell}=0 \text { (assumed in all the models under discussion). }
$$

The term $\dot{Q}_{f}$ includes the heat of pyrolysis.

In the following sections we will discuss the source term for eqn. (12) and discuss the differences which occur in each of the models.

\section{RADIATIVE AND CONVECTIVE LOSS AND GAIN}

The radiative and convective heat luss and gain terms are cuntained in eqns. (12c, 12d) and are represented by the term $\dot{Q}$. The formalism used here is somewhat more complex than is needed strictly for loss and gain to a layer; however, the same terms will show up again in discusslon of the subsidiary equations that describe heating of the walls, flour, ceiling, and uther ubjects. Suurces of heat which increase internal energy are positive. Once again $\dot{Q}=\dot{Q}_{R}+\dot{Q}_{c}+\dot{Q}_{f}+\dot{Q}_{j}$. 


\subsection{Radiative Loss and Gain}

The terms which contribute heat to an absorbing layer are the same (in form) for all layers so we will discuss these in terms of a general layer contribution. Radiation can leave a layer by going to another layer, to the walls, exiting through a vent, or heating up an object. Similarly, a layer can be heated by absorption of radiation from these surfaces and objects. The formalism which we will use for the geometry is that used by Siegel and Howell [17] and is shown in figure (1). The radiative transfer can be done with a great deal of generality; however, most models at least make the assumption that zones and surfaces either radiate and absorb like a black body, or a grey body with some constant emissivity $(\varepsilon<1)$.

A further assumption consonant with the stratifled zone assumption is that emission and absorption are constant throughout a gas layer. In application to a two layer model, the assumption is made in all implementations that the lower layer is diathermous. This is not a necessary assumption but greatly simplifies the radiation transfer calculations. In future work, the case of a lower layer which can emit and absorb should probably be included, especially if interlayer mixing is included.

The radiation transfer problem is always broken into two parts: first is transfer to and from gases, walls and surfaces; second is transfer to and from objects and fires. There are two reasons for such a division. The first is that, although complicated, radiation to and from walls, gases and surfaces can be treated more or less completely. The primary problem which arises here is that not a sufficient amount of information is known about wall emissivity. For objects and fires, however, not only are the absorption and emission coefficlents not well defined, the geometrical factors are not well defined and may change in time as well. Usually the models assume some average shape for the flame and plume and make reasonable estimates for the various view factors. For the most part, the discrepancy is not important. However, 
when flashover is about to occur, this is probably not a valid assumption. Furthermore, with current fire sources, positive feedback may increase the pyrolysis rate and may lead to unstable numerical solutions. For these reasons, we will describe the two sources of radlation transfer separately.

The notation used for the wall, gas, surface interaction is shown In figure (1). All of the zone models can be cast into this form. The primary differences are the sophistication with which the geometrical factors are calculated, and the approximations which are used in finding the emissivity and transmission factors for the layers. With the assumption of blackbody emission, and using eq. (17.20) of Siegal and Howell [17] we obtain

$$
\begin{aligned}
\sum_{j=1}^{N}\left[\frac{\delta_{k j}}{\varepsilon_{j}}-F_{k j} \tau_{k j}\left(\frac{1-\varepsilon_{j}}{\varepsilon_{j}}\right)\right] \dot{Q}_{j}= \\
\quad \sum_{j=1}^{N}\left[\left(\delta_{k j}-F_{k j} \tau_{k j}\right) \varepsilon_{j} \sigma T_{j}^{4}-F_{k j} \bar{\alpha}_{k j} \varepsilon_{g} \sigma T_{g}^{4}\right]
\end{aligned}
$$

for radiation to surface (k) from surface $(j)$.

Of interest here is the net influx of radiation to the upper gas layer, which can be written as

$$
\dot{Q}_{g}=-\sum_{k} \dot{Q}_{k} A_{k}
$$

The notation used is:

$$
\begin{aligned}
F_{k j} & =\text { geometrical view factor of surface }(k) \text { by surface }(j) \\
\tau_{k j} & =\text { transmission coefficlent from surface }(k) \text { to surface }(j) \\
\bar{\alpha}_{k i} & =\text { absorption coefflcient } \\
\dot{Q}_{j} & =\text { net radiation flux to surface }(j)-\text { watts } / m^{2} \\
\dot{Q}_{g} & =\text { net radiation to the upper gas layer - watts }
\end{aligned}
$$




$$
\begin{aligned}
\dot{\mathrm{Q}}_{\mathrm{u}}, \dot{\mathrm{Q}}_{\ell}= & \text { net radiation to the upper and lower layer (boundary) } \\
& \text { surfaces } \\
\sigma= & \text { Stephan-Boltzman constant }=5.67 \times 10^{-8} \text { watts } / \mathrm{m}^{2} \mathrm{~K}^{4} \\
\mathrm{~L}= & \text { mean beam length }-(\mathrm{m}) \\
\alpha= & \text { absorption coefficient of the upper gas layer }\left(\mathrm{m}^{-1}\right)
\end{aligned}
$$

We assume that the grey, upper zone, can be treated as an equivalent radiating sphere with a mean beam length given by

$$
\mathrm{L}=4 \mathrm{~V} / \mathrm{A}
$$

where $V$ is the volume of the gas and $A$ is its surface area. This yields an effective emissivity for the upper layer of

$$
\varepsilon_{g}=1-\exp (-\alpha L)
$$

For a two zone model, with the assumption that the lower layer is diathermous, we have the two terms, as shown in detail by Tanaka [10]

$$
\dot{Q}_{u}=A_{u} \varepsilon_{u} I_{u} / D, \dot{Q}_{\ell}=A_{\ell} \varepsilon_{\ell} \Pi / D \text { and } \dot{Q}_{g}=-\dot{Q}_{u}+\dot{Q}_{\ell}
$$

plus additional loss terms for a vent. The factors $A_{u}$ and $A_{\ell}$ are the upper and lower boundary surface areas minus the vents and other openings. The terms are given by

$$
\begin{aligned}
D & =\left\{1-\left(1-\varepsilon_{u}\right)\left(1-\varepsilon_{g}\right) F_{u u}\right\}\left\{1-\left(1-\varepsilon_{\ell}\right) F_{\ell \ell}\right\} \\
& -\left\{\left(1-\varepsilon_{u}\right)\left(1-\varepsilon_{\ell}\right)\left(1-\varepsilon_{g}\right)^{2} F_{u \ell} F_{\ell u}\right\} \\
\Pi_{u} & =\left[\left\{1-\left(1-\varepsilon_{g}\right) F_{u u}\right\}\left\{1-\left(1-\varepsilon_{\ell}\right) F_{\ell \ell}\right\}\right. \\
& \left.-\left\{\left(1-\varepsilon_{\ell}\right)\left(1-\varepsilon_{g}\right)^{2} F_{u \ell}{ }^{F}\right\}\right] \sigma T_{u w}^{4} \\
& -\left(1-\varepsilon_{g}\right) F_{u \ell} \varepsilon_{\ell} \sigma T_{\ell w}^{4}-\left[1+\left(1-\varepsilon_{\ell}\right)\left\{\left(1-\varepsilon_{g}\right) F_{u \ell} F_{\ell u}-F_{\ell \ell}\right\}\right] \varepsilon_{g} \sigma T_{g}^{4}
\end{aligned}
$$




$$
\begin{aligned}
\Pi_{\ell} & =\left[\left(1-\left(1-\varepsilon_{u}\right)\left(1-\varepsilon_{g}\right) F_{u u}\right\}\left(1-F_{\ell \ell}\right)-\left(1-\varepsilon_{u}\right)\left(1-\varepsilon_{g}\right) F_{u \ell_{\ell u}}{ }^{2} T_{\ell w}^{4}\right. \\
& -\left(1-\varepsilon_{g}\right) F_{\ell u} \varepsilon_{u} \sigma T_{u W}^{4} \\
- & {\left[\left(1-\left(1-\varepsilon_{u}\right)\left(1-\varepsilon_{g}\right) F_{u u} F_{\ell u}+\left(1-\varepsilon_{u}\right)\left(1-\varepsilon_{g}\right) F_{\ell u}\right] \varepsilon_{g} \sigma T_{g}^{4}\right.}
\end{aligned}
$$

Equations (14-16) represent the most general case. These equations can be simplified somewhat if we do not consider the effect of grey walls. Then we have, as an example,

$$
\varepsilon_{\ell}=\varepsilon_{u}=1
$$

With this approximation, the factors become

$$
\begin{aligned}
& \dot{Q}_{\mathrm{u}}=\mathrm{A}_{\mathrm{u}} \mathrm{P}_{\mathrm{u}} / \mathrm{D} \\
& \dot{\mathrm{Q}}_{\ell}=\mathrm{A}_{\ell} \mathrm{P}_{2} / \mathrm{D}, \\
& \mathrm{D}=1 \text {, } \\
& I_{u}=\left\{1-\left(1-\varepsilon_{g}\right) F_{u u}\right\} \sigma T_{u w}^{4}-\left(1-\varepsilon_{g}\right) F_{l \ell} \sigma T_{l W}^{4}-\varepsilon_{g} \sigma T_{g}^{4} \\
& \Pi_{\ell}=\left\{1-F_{\ell \ell}\right\} \sigma T_{\ell w}^{4}-\left(1-\varepsilon_{g}\right) F_{\ell \ell} \sigma T_{u w}^{4}-F_{\ell u} \varepsilon_{g} \sigma T_{g}^{4} \\
& \text { where } F_{u u}=1-\frac{A_{d}}{A_{u}}, F_{u \ell}=\frac{A_{d}}{A_{u}}, F_{\ell u}=\frac{A_{d}}{A_{\ell}} \text {, and } F_{\ell \ell}=1-\frac{A_{d}}{A_{\ell}} \text {. }
\end{aligned}
$$

Finally, the net radiation to the upper gas layer is given by

$$
\dot{Q}_{g}=-\sum_{k} \varepsilon_{k} A_{k} \pi_{k} / D
$$




\subsection{Implementation of Radiation Formulae}

The various models differ in the number of these terms which are included, and when included, the form taken for the view factors and calculation of emissivity. Table II shows the level of completeness of each mode1.

Table II

\begin{tabular}{ll} 
Model & \multicolumn{1}{c}{ Comments } \\
NBS-II & Complete \\
No radiative transfer - effective radiative loss \\
proportional to $\mathrm{H}_{\mathrm{C}}$ \\
Complete - no radiation through vents, does not \\
include radiation from fire source
\end{tabular}

NOTE: "complete" refers to the formalism discussed above.

Two terms which have not yet been discussed are first, the radiation due to a fire source, and second, the radiation interchange through a vent. The former is a very difficult problem in that fire source is generally very trregular in shape, and usually changing in time. The latter is done very much in an ad-hoc manner, that is an overlay on the usual radiation treatment, primarily due to the difficulty of calculating the actual configuration factors for vents and other arbitrary openings. For these reasons, the effects of these two sources of radiation will simply be presented for the models where appropriate. The source terms for radiation exchange with vents, walls and a zone are 
shown in Table III for the three models whlch have a complete radiative transfer scheme. This example ts presented for comparison purposes and is for $\varepsilon_{u}=\varepsilon_{\ell}=1$. The notation is that used In figures (1) and (2), and glven earlier. All three use $\varepsilon_{g}$ (lower) $=0.0$; therefore we use the notation $\varepsilon_{g}$ refers to the upper gas layer only, whereas $\varepsilon_{u}$ and $\varepsilon_{\ell}$ refer to the upper and lower wall emlssivities, respectively.

TABLE III

Model

$\dot{Q}_{R}$

\begin{tabular}{|l|c|c|}
\hline NBS-I & $-\sigma\left[\varepsilon_{g} T_{u}^{4} A+\left(1-\varepsilon_{g}\right) T_{u w}^{4}\left(A_{u}+A_{u v}\right)-T_{u w}^{4} A_{u}-\varepsilon_{g} T_{\ell w}^{4} A_{d}-T_{a}^{4} A_{u v}\right]+1 / 2 E_{f}$ \\
Harvard & $-\sigma\left[\varepsilon_{g} T^{4} A\right.$ & $\left.-\varepsilon g T_{u w}^{4}{ }^{A}{ }^{4}-\varepsilon_{g} T_{\ell w}^{4}\left(A_{d}+A_{\ell v}\right)\right]+1 / 2 E_{f} f\left(Z_{u}, Z_{\ell}\right)$ \\
BRI & $-\sigma\left[\varepsilon_{g} T_{u}^{4} A\right.$ & $\left.-\varepsilon_{g} A_{u} T_{u w}^{4}-\varepsilon_{g} A_{d} T_{\ell w}^{4}\right]$ \\
\hline
\end{tabular}

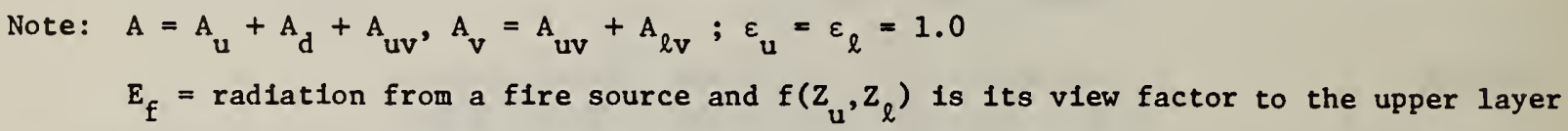

\subsection{Convection}

Convection is the mechanism by which the gas layers lose (or gain) energy to the walls. The other physical process, conduct lon, which is intimately connected with convection, will be discussed in the section on subsidiary equations - heat loss by the wall and heating of interior objects.

The basic formulation is the same for all models which incorporate convective heat loss. The primary differences lie in the method used to change the wall temperature, redistribute energy and the calculation of the heat loss coefficlent - $h_{c}$. Table IV summarizes the results. 
These formulae are applied in the models in a general way although very little data exists for detailed validation. The formula used in NBS-I is specific to crib fires in a single room and that used in NBS-II was an effort to make such a detailed comparison between a model and a part Lcular experiment.

TABLE IV

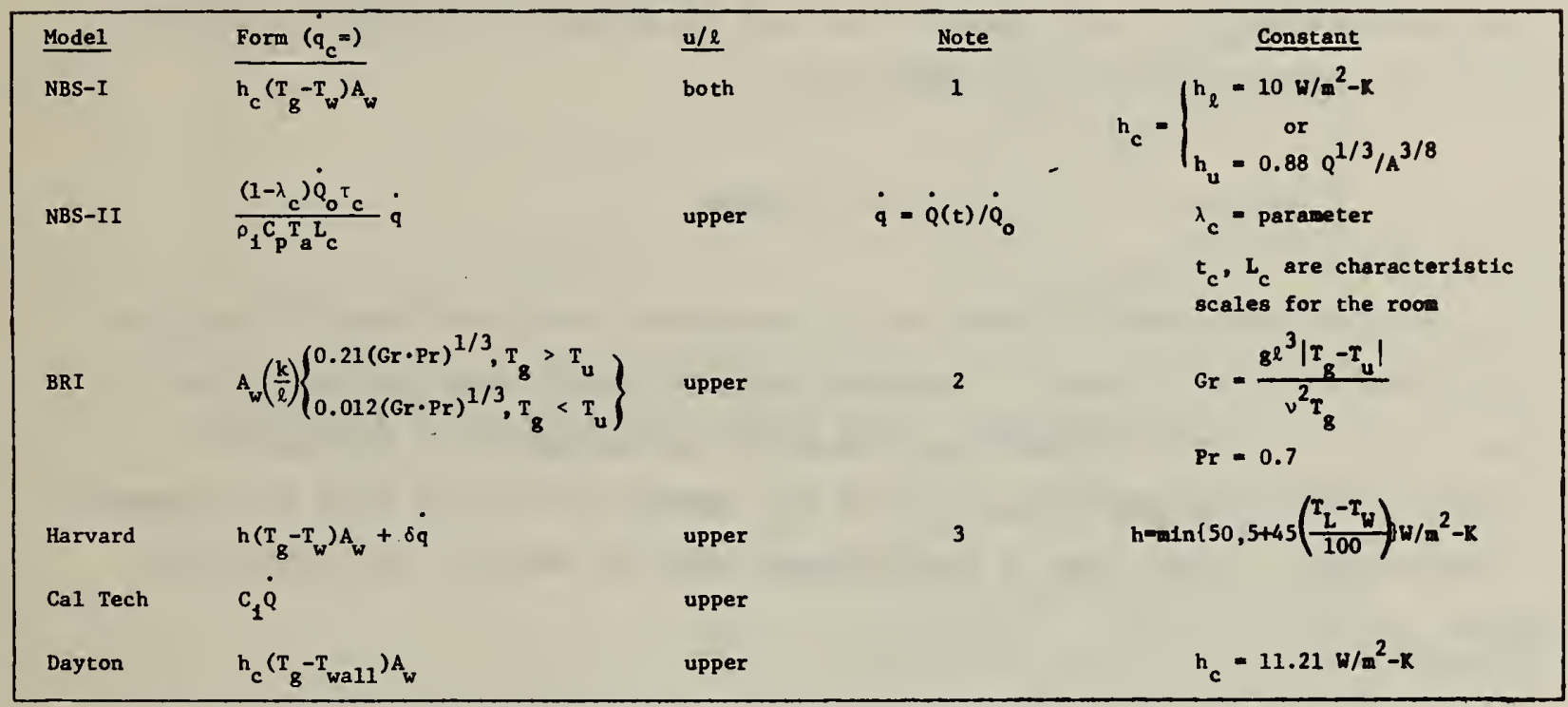

1. Applies to both upper and lower walls; as a slice of the layer reaches a new section of the wall, the wall is assumed to equilibrate instantaneously.

2. $v=7.18 \times 10^{-10} \mathrm{~T}^{7 / 4}, \mathrm{~g}=9.8 \mathrm{~m} / \mathrm{sec}, \ell=$ length over which convective heat transfer takes place. Applies to the uppẹr layer only.

3. Applies to upper surface only; " $\delta "$ " 18 an approximation for the amount of energy required to bring the new slice of heated wall to the same conditions as the hot upper wall. As the layer retreats $\delta q 18$ set to zero, that 1s, no energy is put into the lower layer by cooling of this new slice of lower wall.

$$
\begin{aligned}
& \delta \dot{q}=\left[\int^{t} \dot{q}_{c} d t\right]\left[\dot{\varepsilon}_{u} / \varepsilon_{u}\right]\left[A_{w}\right] \text {, where } A_{w} \text { is the area of cefling, and } \\
& \dot{\varepsilon}_{u} \text { (thermal energy in the upper layer) }>0
\end{aligned}
$$

\section{ENTHALPY AND MASS FLUX}

The primary mechanisms which provide for mixing and transfer of mass and energy between the two layers are flow provided via the plume and mixing at a door and other vents. These phenomena are complicated if one considers the general multiroom case. In the following section we will consider the situation as it exists in current models with one 
roum vented to an ambient atmusphere and make no attempt tu describe the general interaction. In the case of the plume, this implies that the plume starts at a fire suurce and no cumbustion uccurs during the ascent of a smoke parcel. As the gas rises, it entrains air from the lower layer. This mixture is then deposited in the upper layer. For the problem of vent fluw, the exterior wlll be a single "layer" whose pressure is calculated from hydrustatic equilibrium at temperature $\mathrm{T}_{\mathrm{a}}$. This is the external air temperature and is generally sumewhat (usually) below $T_{e}$, the external wall temperature.

\subsection{Plumes}

A fire generates a plume which transpurts mass and energy from the fire into the upper layer. In addition, the plume entrains mass from the lower layer and transpurts this mass and energy into the upper layer. The energy and mass $\left(\dot{Q}_{f}\right.$ and $\dot{m}_{f}$ ) generated by the fire are cummun to all models. The form of entrainment used by each of the models is shown in Table $V$.

There are several pussible problems in the implementation of plume theury in numerical applicatiuns. Specifically, the enthalpy which is generated by a heat suurce due to cumbustion is relative to sume reference temperature. It is important, to be a self-cunsistent, to use this same temperature as a reference in calculating the energy necessary for pyrulysis and the net energy added to the fuel to bring it up to the pyrolysis temperature. In particular, in order to go from the fuel temperature to the pyrolysis temperature, a certain amount of energy must be subtracted from the lower layer; of course there is also sume radiative heating from the fire and from both layers. Finally, In using Table $V$, one must be careful that the furmula is applicable to the problem. For example, the form given for NBS-I is specific to a crib fire. 


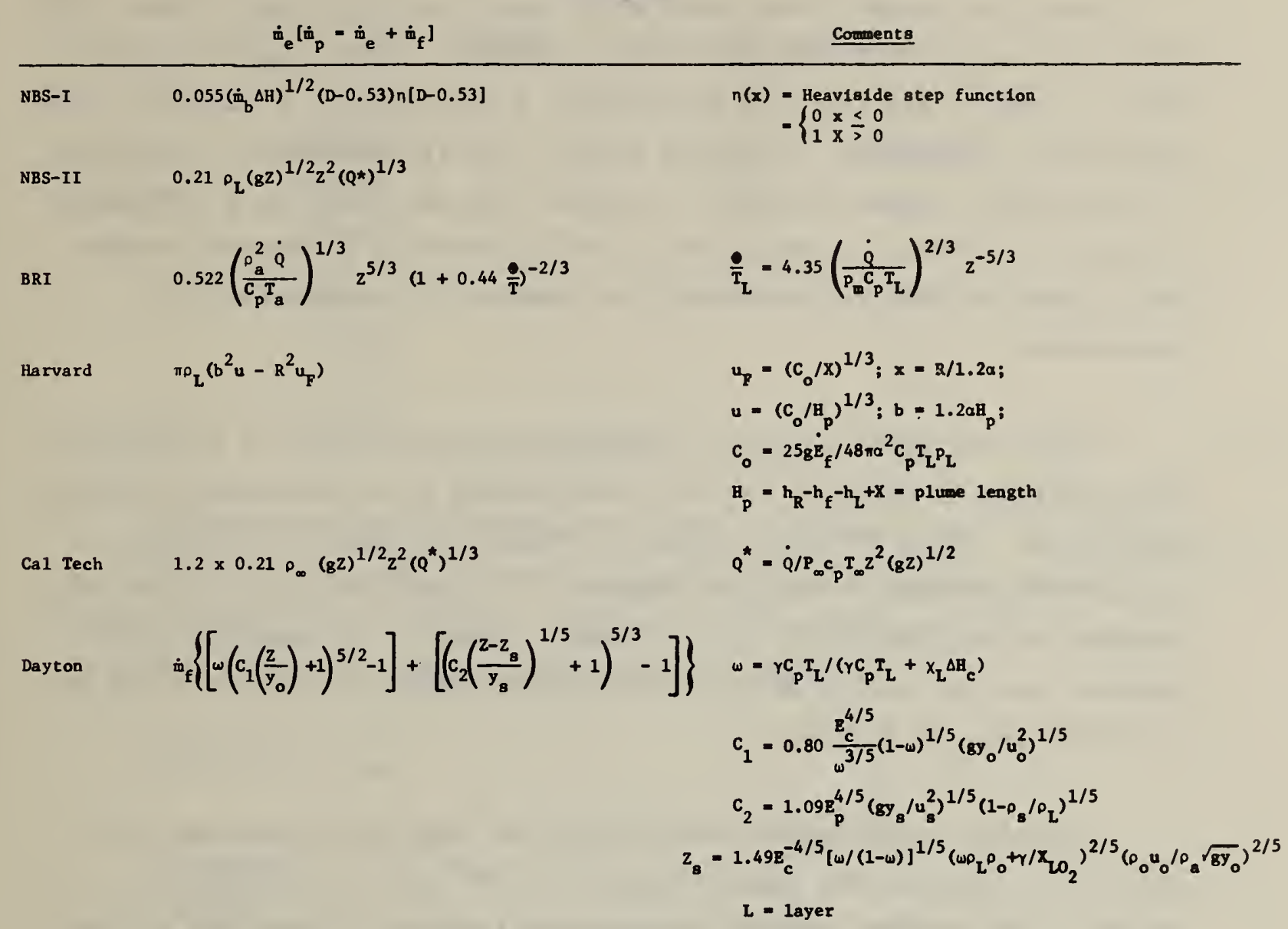

\subsection{Door Jets and Mixing}

Flow at vents is governed by the pressure difference across a vent whlch occurs at each zone level. In the control volume approximation the general momentum equation for the zones is not solved (a possible source of error). Instead, the momentum transfer at the boundaries is included by using Bernoulli's solution for forced flow. This is augmented for restricted openings by using "flow coefficients." These latter modifications deal with the problem of constriction of velocity streamlines at an orifice. As shown in figure (3), the general case for multilayer flow can be quite complicated. 
There are actually two cases which apply to this type of flow. The first, and usually thought of in fire problems, is the case where atr, smoke or some other fluid is pulled from a compartment by buoyancy. The second type of flow is the piston effect, and is particularly important in the initial stages of a fire. Rather than depending on a difference in density between two gases, the flow is forced by a pressure difference across an orlfice generated, for example, by combustion in a compartment.

Figure (4) shows the four configurations which will be considered. The situation is speciflc for one room venting to an unconfined, ambient atmosphere. Cases ( $b$ and $c$ ) shown in figure (4) can be considered as two manifestations of the same geometry. An important distinction must be made in the physics of the two cases, however. In case (b) both buoyancy and the piston effect are present whereas in case (c), the flow is driven only by buoyancy.

A further complication which arises is that of determining the position of the neutral plane relative to the layer discontinuity height. The somewhat complex interaction leads to a large set of flow conditions even in the case of a single compartment, at least for cases (c) and (d). In general, all models proceed on the basis that flow is governed by Bernoulli's equation at an opening and the driving force is a combination of the ground (reference) pressure and the hydrostatic change in pressure as a function of height. The differences in the implementation of the models lie in the formalism actually used to calculate the flow, which terms are included (i.e., mixing between the upper and lower layers), and which regimes are included.

Table VI shows which of the four regimes (filling, buoyant, flow and choked flow) are included in each model. The terms are explained in figure (4). 
Table VI

Flow regimes included in each model

$\begin{array}{lc}\frac{\text { Model }}{\text { NBS-I }} & \text { Regimes } \\ \text { NBS-II } & \mathrm{c} \\ \text { BRI } & \mathrm{a} \\ \text { Harvard } & \mathrm{a}-\mathrm{d} \\ \text { Cal Tech } & \mathrm{a}-\mathrm{c} \\ \text { Dayton } & \mathrm{a}-\mathrm{c} \\ & \mathrm{a}-\mathrm{c}\end{array}$

The most systematic approach is done by Tanaka [18]. Therefore we will use this notation, since all other models can be cast into this form. The one piece which is missing from the BRI model is the intraroom layer mixing which will be taken from NBS-I.

The notation is:

$$
\begin{aligned}
S & =\text { smoke } \\
A & =\text { air } \\
1 j & =\text { flow from room } i \text { to room } j \\
P & =\text { reference pressure (at the floor) }
\end{aligned}
$$

The order of the letters indicate which type of layer is flowing into which other types. For example, $\mathrm{SA}_{\mathrm{jl}}$ indicates that fluld from a smoke layer in room ( $j$ ) is flowing into an air layer in room ( $i$ ). of course, in the present case, only one room exists with the remalning space being an infinite, ambient atmosphere. Therefore, only the term $\mathrm{AA}_{12}, \mathrm{SA}_{12}, \mathrm{AA}_{21}$, and $\mathrm{AS}_{21}$ can be non-zero. Table VII shows the various terms where the notation is shown in figure (5).

Mixing between the upper and lower zones can be important at doorways, and possibly at the walls. Little energy will be transported by this mechanism, but it does provide a means by which smoke can be injected into the lower layer, thereby providing a means to change the 
optical propertles of that layer. At present, the only work which Incorporates this phenomena is that of culntiere et al. [13], and is for vents only. The contribution to the mass input to the lower layer is given by

$$
\mathrm{AA}_{21} / \mathrm{SA}_{12}=0.5\left(\mathrm{~T}_{\mathrm{a}} / \mathrm{T}_{\mathrm{g}}\right) \frac{\mathrm{N}-\mathrm{Z}}{\mathrm{N}} .
$$

TABLE VII

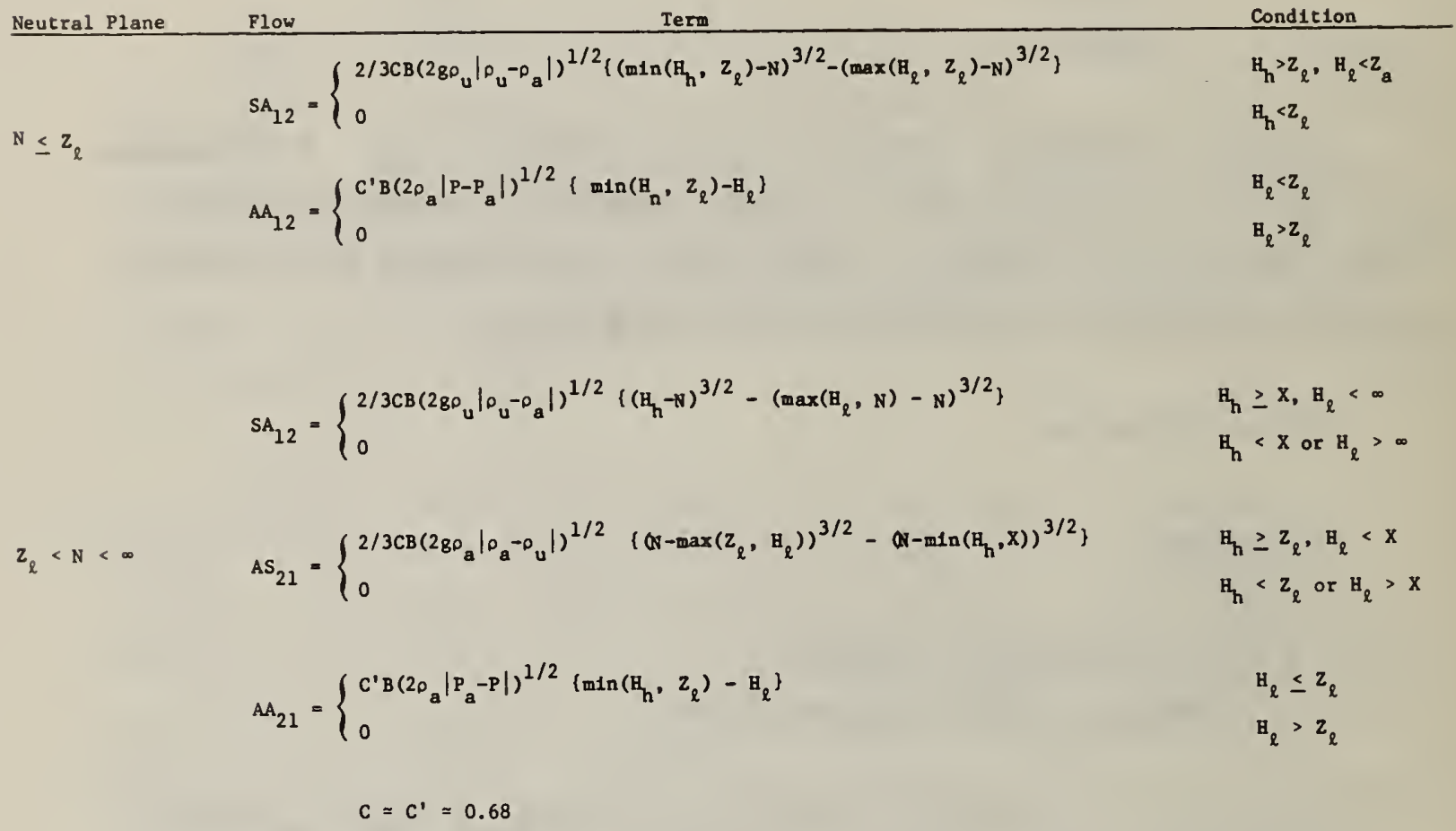

\subsection{Special Cases and Selection Tables}

Figure 6 shows the possible combinations of the neutral plane and vent configurations. The neutral plane is given from the hydrostatic equation by knowing the pressures at the floor and realizing that at the neutral plane the pressure differential is zero. For the single room case, there is only one possible choice for the neutral plane. If the pressures are equal at the floor and everywhere (within a vent) the densities are the same, then the neutral plane is well above the opening height $\left(H_{u}\right)$. If, however, the situation is as shown in figure (5), then we have 


$$
P_{1}(Z)=P-\rho_{\ell} g Z_{\ell}-\rho_{u} g\left(Z-Z_{\ell}\right) \quad \text { (internal) }
$$

and

$$
P_{e}(z)=P_{a}-\rho_{a} g z
$$

At the neutral plane we have $P_{i}(N)=P_{e}(N)$ and therefore

$$
N=\left(\frac{P_{a}-P}{\rho_{a}-\rho_{u}}\right)+\left(\frac{\rho_{\ell}-\rho_{u}}{\rho_{a}-\rho_{u}}\right) Z_{\ell}
$$

defines the posttion of the neutral plane. Normally the flow coefficients will be approximately equal

$$
C \sim C^{\prime} \sim 0.6-0.7
$$

for both air and smoke.

\section{SUBSIDIARY EQUATIONS}

The term "subsidiary equations" covers all of the interactions which do not directly influence mass or energy balance of the upper or lower layer, or terms which are not yet on a firm mathematical basis. The former includes effects such as thermal conductivity through walls and an example of the latter would be fire sources and the effect on them of radiation for the upper gas layer.

\subsection{Fire Source}

$x^{5}$

The most difficult aspects of modeling a fire (source) are deciding where the fire actually burns and elucidating the effect of radiation on the fuel source. The latter problem includes both self-radiation, that is radlation from the flame back to the fuel source as well as radlation from walls, layers and other objects to the fuel. Many of the models avoid the problem by specifying the burning rate as a function of $t$ ime. For some purposes this is adequate. However, for studying flashover, multiple ignition and simllar problems, a fire model must be spectfled. 
The heat release rate per unit mass being $h_{c}$ (generally not a strong function of temperature), the enthalpy flux into the upper layer is

$$
\dot{Q}_{f}=h_{c} \dot{m}_{v}-c_{p}\left(T_{u}-T_{v}\right) \dot{m}_{v}-\dot{Q}_{p}
$$

Essentially, the energy introduced into the upper layer is a product of the heat release rate at the pyrolysis temperature with a reduction for the energy required to gaslfy the fuel and subsequent pyrolysis.

For a spectfled burning rate, this is sufficient. In order to treat a self-consistent fire, however, one must include the interaction of a fire source with its environment. A self-consistent fire source must include the effects of oxygen vitiation, radiation to the fuel surface, radiation by the fuel surface, and heating by conduction. The NBS-I, Harvard and Dayton models have fire source algorithms whlch include one or more of these effects, as shown in Table VIII.

Table VIII

$\begin{array}{ll}\text { NBS-I } & \text { Oxygen, radiation } \\ \text { Harvard } & \text { Radiation, re-radiation, conduction } \\ \text { Dayton } & \text { Oxygen, radiation }\end{array}$

All three models attempt to include the effects of radiation from both the upper layer, walls and the flame itself. Clearly, prior to Ignition, the radiation from "other" sources is most important. However, once ignition occurs, radiation from the flame to walls, the gas layer and other objects should generally dominate. In addition, the Harvard model includes re-radiation from the fuel source itself. This latter effect should not be Important for gas burners or pool fires but may be effective in reducing the burning rate of charring materlals. 
An important difference in the models is the method of including the geometrical (view) factors. As before, the intent is to include only the radiation which an object "sees." A fire changes shape in time, and rather quickly at that. This leads to the use of approximate flame shapes, the most common being cones (Harvard) or cylinders (NBS-I, Dayton). When including incident radiation due to walls and the gas layers, a complete treatment of the problem allows for absorption by the plume and flame. Finally allowance has to be made for effects of oxygen vitiation. In princlple, a more complete kinetics scheme should be included, espectally as the detalled specles which are released in combustion become accessible experimentally. Nevertheless, the effect of oxygen (or lack) must be taken into account. The (NBS-I) model does these in an ad hoc but reasonably effective way, namely

$$
\dot{\mathrm{m}}_{\mathrm{f}}=\dot{\mathrm{m}}_{\mathrm{free}}+\dot{\mathrm{m}}_{\mathrm{R}}+\dot{\mathrm{m}}_{\mathrm{O}}
$$

where $\dot{\mathrm{m}}_{\mathrm{f}}=$ free burning rate of a fire

$\dot{\mathrm{m}}_{\mathrm{R}}=$ enhancement due to radiation effects

$\dot{\mathrm{m}}_{\mathrm{o}}=$ decrement due to vitiation

For NBS-I, which considered the burning of cribs, the $\dot{\mathrm{m}}_{\mathrm{R}}$ term is given by

$$
\dot{\mathrm{m}}_{\mathrm{R}}=\frac{\dot{\mathrm{q}}_{\text {top }} \cdot \mathrm{A}_{\text {top }}+\dot{\mathrm{q}}_{\text {side }} \cdot \mathrm{A}_{\text {side }}}{\mathrm{L}_{\text {vap }}}
$$

where $\mathrm{L}_{\text {vap }}$ is the gasification energy and is a measured quantity. For this particular experiment, $\mathrm{L}_{\text {vap }}$ ignored the contribution (decrement) due to heating of the fuel. Thus to do this problem more generally a loss term, $\dot{m}_{\text {target }}$ should be Included in eqn. (19). The term "Top" and "Side" refer to the parts of the cribs which were being nodeled. The Harvard model proceeds in a similar fashion except that the view factors which determine the $\dot{q}$ term are calculated numerically based on the object position and geometry relative to the celling and walls. In the case of NBS-I, the view factors are calculated analytically, once again based on the geometry of the room and object (fire source). One aspect 
of the Harvard model is the inclusion of absorption of the flame radiation by the fire source.

oxygen deprivation has two parts. The first is the oxygen concentration near the fuel source. The second is the amount of burning which occurs in the plume (a flame) above the fuel source. This latter is tmportant since, as the upper layer descends, the functional form of combustion changes. The NBS-I model does this by

$$
\dot{\mathrm{m}}_{\mathrm{o}}=-\dot{\mathrm{m}}_{\text {free }}\left\{1-\frac{\mathrm{Y}_{\mathrm{ox}}}{0.23}\right\}
$$

and the Harvard model accomplishes this same effect by changing the size of the cone of the flame. As the layer moves down, the cone is truncated, reducting the pyrolysis rate, thus reducing the mass flow. The Dayton model accomplishes this using a method similar to NBS-I. The Dayton model uses the Steward [20] and Fang [21] plume models (see Table V), however.

The last piece in this analysis concerns the pyrolysis itself. In addition to the problem of heating the fuel from its reference state $T_{R}$, there is also the problem of a phase change, for example, from solid to gas, where the combustion finally occurs. From the point of view of modeling a fire, the only reason to be concerned with this process is that a phase change is sensitive to temperature and pressure; thus the fire history affects the burning rate $\dot{\mathrm{m}}_{\dot{i}}$. An important part of this process is the production of toxic substances, such as carbon-monoxide and cyanide. Since this is in large part the motivation for studying the fire problem, a great deal more effort must be spent on this aspect of modeling a fire source.

As is obvious, our understanding of the fire source itself is minimal. Further, the source to be used is specific to the problem to be studied. At this point there is no agreed upon way to include a general, self-consistent fire source in a model. 


\subsection{Radiation Between Objects}

The calculation of radiation effects between objects suffers from problems similar to those of the fire source itself. Interobject radiation is an important phenomenon only if multiple targets are present and one is interested in flashover. The only two models which address this issue are the Dayton [2] and Harvard models [19]. The primary difficulty arises in calculating view factors between the objects. This has an analogy in several other flelds. One must calculate the projection onto a surface (the target) of the surface subtended by the solid angle (view factor) of the emitter. Except for simple objects such as spheres and planar surfaces, this calculation is difficult. Current research in modeling of solid objects, which deals with plecewise continuous approximations to a surface, will aid in automating and generalizing these calculations. At the present time, however, the methods used in the above mentioned models will have to suffice.

\subsection{Conduction}

Conduction of heat through solids occurs in two places: the compartment walls and interior objects. The techniques used are similar for both cases. Generally a slab is cut into $N$ intermediate slices (N+l nodes). Then the heat conduction equation

$$
\frac{\mathrm{dT}}{\mathrm{dt}}=\nabla(\alpha \nabla \mathrm{T}) \simeq \alpha \nabla^{2} \mathrm{~T}=\alpha \frac{\partial^{2}}{\partial \mathrm{x}^{2}} \mathrm{~T}
$$

is solved for each element of this finite grid. On elther side of a fintte slab, boundary conditions are imposed for radiation (net) and convect lve heating and cooling. The number of nodes is chosen to reduce the error to some reasonable value, say $5 \%$. Use of $\mathrm{N}>20$ will improve precision without a concomitant increase in accuracy. For very thin walls only the surface nodes are necessary.

For the first time step, an initial temperature profile must be assumed. The usual assumption is uniform ambient temperature throughout 
the solid. After the flrst step, the previous distribution can be assumed. As can be seen, this implementation differs markedly from the usual "control volume" approach.

The actual calculation usually employs a finite central difference, forward (explicit) time step scheme.

$$
T_{j}(t+\delta t)=(1-a \delta t) T_{1}(t)+\frac{a \delta t}{2}\left(T_{j+1}(t)+T_{j-1}+1\right)
$$

with $\delta t=t$ ime step interval

$a=\operatorname{different} L a l$ coefficlent $=2 \alpha /(\delta \mathrm{x})^{2}$

At the surface, the boundary condition

b $\delta t \dot{q}$

with $b=(\rho c \delta x)^{-1}$,

$c=$ heat capacity per unit mass.

The flux $\dot{q}$ may arise from convection or radlation and may be positive or negative.

When this formulation is applied, particularly to walls, cellings and floors, a decision must be made as to the division of surfaces which are in the upper and lower layers, and what is done to the energy balance as the wall surface immersed in each layer changes. This method of heat conduction is done by NBS-I, BRI, Harvard and Dayton, although the Dayton implementation is not as complete as the others.

An alternative is to use an average conduction coefficient and assume that the energy loss is proportional to the temperature difference times this heat loss factor. Such a formulation is applicable to heat loss in early stages of a fire when only the celling is affected and principally by convective heating. At later stages, however, this model is clearly not appropriate. The models which use this method are NBS-II and Cal Tech. 


\section{CONCLUSIONS}

We have examined the models which use the control volume concept in analyzing fire growth and spread. While none of the models is complete, all of them have features which can be well utilized in the formation of a general fire model. These features reflect the specialties of the respective authors.

\section{REFERENCES}

[1] Quintiere, J.G. and McCaffrey, B.J., The Burning of Wood and Plastic Cribs in an Enclosure: Volume I, Nat. Bur. Stand. (U.S.), NBSIR 80-2054 (1980).

[2] MacArthur, C.D., Dayton Aircraft Cabin Fire Model Version 3, Volume I and II, University of Dayton Research Institute (1981).

[3] Emmons, H.W., The Prediction of Fires in Bulldings, The Seventeenth Symposium (Internationa1) on Combustion, The Combustion Institute, Pittsburg, PA (1978).

[4] Mitler, H.E., The Physical Basis for the Harvard Computer Fire Code, Home Fire Project Tech.,Rept. 非, Harvard University (1978).

[5] Cooper, L.Y., Estimating Safe Available Egress Time from F1res, Nat. Bur. Stand. (U.S.), NBSIR 80-2172 (1981).

[6] Zukoski, E.E. and Kubota, T., Two-Layer Modeling of Smoke Movement in Building Fires, Fire and Materials 4, 17 (1980).

[7] Zukoski, E.E., Kubota, T. and Cetegen, B., Entrainment in Fire Plumes, NBS-GCR 80-294 (1980).

[8] Emmons, H.W., The Growth of Fire Science, Fire Safety J. $\underline{3}, 95$ (1980).

[9] Emmons, H.W., The Calculation of a Fire in a Large Bullding, ASME $81-\mathrm{HT}-2$ (1981).

[10] Tanaka, T., A Mathematical Model of a Compartment Fire, Building Research Institute (Japan), Research Paper \#70 (1977).

[11] Tanaka, T., A Model of Fire Spread in Small Scale Buildings, Building Research Institute (Japan), Research Paper $\#^{79}$ (1978) and \# 84 (1980). 
[12] Quintiere, J.G., McCaffrey, B.J. and Kashiwag1, T., A Scallng Study of a Corridor Subject to a Room Fire, Comb. Scl. and Tech. 18, 1 (1978).

[13] Quintiere, J.G., Steckler, K. and McCaffrey, B., A Model to Predict the Conditions in a Room Subject to Crib Fires, First Speclalists Meeting (International) of the Combustion Inst., Talence, France (1981).

[14] Quintiere, J.G., Growth of Fire in Building Compartments, ASTM Special Technical Publication 614 (1977); The Spread of Fire from a Compartment - A Review, ASTM STP 685 (1979).

[15] Rockett, J.A., Fire Induced Gas Flow in an Enclosure, Comb. Sci. Tech. 12, 165 (1976).

[16] Quintlere, J.G., An Approach to Modeling Wall Fire Spread in a Room, Fire Safety J. 3 , 201 (1981).

[17] Siegel, R. and Howell, J.R., Thermal Radiation Heat Transfer, McGraw Htll Book Co., New York (1981).

[18] Tanaka, T., A Model of Multiroom Fire Spread, to be published as a Nat. Bur. Stand. Internal Report (1983).

[19] Mitler, H.E. and Emmons, H.W., Documentation for CFC V, The Fifth Harvard Computer Fire Code, Home Fire Project Tech. Rep. \#45, Harvard University (1981).

[20] Steward, F.R., Comb. Sci. and Tech. 2, 203 (1970).

[21] Fang, J.B., Analysis of the Behavior of a Freely Burning Fire in a Quiescent Atmosphere, NBSIR 73-115 (1973). 
A area $\left(m^{2}\right) ; A_{u}, A_{\ell}, A_{d}$ are the upper and lower cumpartment surface areas in cuntact with the upper and lower gas layer, Fig. (1), respectively. $A_{d}$ is the interface area between the upper and lower layers. In section 4.1 , "A" is used as a variable in the flow equations to indicate air.

B width of a vent (m)

$C, C^{\prime}$ flow cuefflclent $\simeq 0.6-0.7$ for both smoke and air

c specific heat $-c_{p}, c_{v}(\mathrm{~J} / \mathrm{kg} / \mathrm{k})$

$\dot{\mathrm{E}} \quad$ energy release rate $(\mathrm{J} / \mathrm{s})$

$F_{i j}$ view factor - relative area of " $i$ " as seen by " $j "$ (dimensionless)

$\mathrm{g}$ acceleration of gravity $\left(9.8 \mathrm{~m} / \mathrm{s}^{2}\right)$

$\mathrm{H}$ height $(\mathrm{m}), \mathrm{H}_{u}, \mathrm{H}_{\ell}$, are the upper and lower limits of a vent Fig. (2)

h enthalpy $(\mathrm{J} / \mathrm{kg} / \mathrm{k})$

$h_{c}$ heat of combustion - theoretical $(\mathrm{J} / \mathrm{kg})$

$1, j$ compartment indices

L mean beam length (m) equivalent upaque sphere

m $\quad \operatorname{mass}(\mathrm{kg})$

$\dot{\mathrm{m}} \quad$ mass flow $(\mathrm{kg} / \mathrm{s}): \quad \dot{\mathrm{m}}_{\mathrm{v}}$ - rate of release of volatiles $\dot{\mathrm{m}}_{\mathrm{e}}$ - entrained into a plume $\dot{\mathrm{m}}_{\mathrm{f}}$ - fuel release $\dot{\mathrm{m}}_{i j}$ - mass entering room "il" from roum " $j$ " $\dot{\mathrm{m}}_{\mathrm{p}}-\mathrm{fluw}$ rate in plume $\left(\dot{\mathrm{m}}_{\mathrm{p}}=\dot{\mathrm{m}}_{\mathrm{f}}+\dot{\mathrm{m}}_{\mathrm{e}}\right)$

N height of the neutral plane (m) 
P pressure (pa): $\bar{P}+P-$ floor reference pressure

$$
\begin{aligned}
& P_{e}-\text { Eqn. (19) } \\
& P_{a} \text { - outside ambient pressure }
\end{aligned}
$$

$\dot{Q}$ rate heat is added or lost $(\mathrm{J} / \mathrm{s})$ :

$$
\begin{aligned}
& \dot{Q}_{u}, \dot{Q}_{l}-\text { upper, lower zones, } \\
& \text { respectively } \\
& \dot{Q}_{f}-\text { fire }\left(h_{c} \dot{\mathrm{m}}_{v}\right) \\
& \dot{Q}_{o}-\text { objects } \\
& \dot{Q}_{R}-\text { radiation } \\
& \dot{Q}_{c}-\text { convection by walls } \\
& \dot{Q}_{g}-\text { radiation added to upper } \\
& \dot{Q}_{k}-\text { radiation from surface " } k " \\
& \dot{Q}_{p}-\text { combustion energy lost by }
\end{aligned}
$$

R gas constant for specific mixture

S smoke - section 4.1

t time (s)

$\mathrm{T}$ temperture $(\mathrm{k}): \mathrm{T}_{\mathrm{a}}$ - ambient

$\mathrm{T}_{c}$ - external wall

$\mathrm{T}_{\mathrm{u}}$ - upper wall

$\mathrm{T}_{\ell}-1$ ower wall

$T_{R}$ - reference temperature for enthalphy flow

$\mathrm{T}_{\mathrm{g}}$ - upper zone temperature

$\mathrm{T}_{\mathrm{v}}$ - volatile temperature

V volume $\left(\mathrm{m}^{3}\right)$ 
a absorption coefficient of upper gas layer $\left(\mathrm{m}^{-1}\right)$, thermal diffusivity $\left(\mathrm{m}^{2} / \mathrm{s}\right)$

$\gamma \quad$ ratio of specific heat $\left(c_{p} / c_{v}\right)$.

$\varepsilon \quad$ emissivity (dimensionless):

$$
\begin{aligned}
& \varepsilon_{1} \text { - surface "I" } \\
& \varepsilon_{g} \text { - upper gas layer } \\
& \varepsilon_{u} \text { - upper compartment surface } \\
& \varepsilon_{\ell} \text { - lower compartment surface }
\end{aligned}
$$

o mass density $\left(\mathrm{kg} / \mathrm{m}^{3}\right)$

$\kappa \quad$ thermal conductivity ( $\mathrm{j} / \mathrm{msk}$ )

$\delta_{i j} \quad$ Kronecker delta $=0 \quad 1 \neq j$

$$
=1 \quad 1=j
$$

Subscripts - In general " $u$ " and " $\ell$ " Indicate upper and lower gas layer, respectively. For area and emissivity variables, reference is to the compartment itself. 
The references contain reasonably complete descriptions of the models. In addition, copies of the computer codes are available from the authors. The following 1 ist is a suggested starting point for each of the models, and is the primary summary of the contents and capabilities of each:

\begin{tabular}{lc} 
Model & References \\
\cline { 2 - 2 } NBS-I & 13 \\
NBS-II & 5 \\
BRI & 18 \\
Harvard & 19 \\
Cal Tech & 6 \\
Dayton & 2
\end{tabular}

To summarize, the most complete transport phenomena are contained in the BRI model, and the most consistent radiation transport in NBS-I. Both the Dayton and Harvard models attempt to deal with the problem of a self-consistent fire source model. As indicated in section 5.1 , this is a difficult problem given our understanding of flames shapes, turbulent mixing and the chemical kinetics of fire oriented combustion.

None of the models handles the numerics well. Part of the problem is mixing differential and algebraic equations, both of which are stiff. (Stiff in this context refers to two or more processes with widely (greater than a factor of ten) varying time constants.) Another part of the problem is in the discreteness of the source functions and their derivatives. Finally, one has to look carefully for possible instabilities in the numerics themselves when the approximation, discussed in section 1 , are made. 


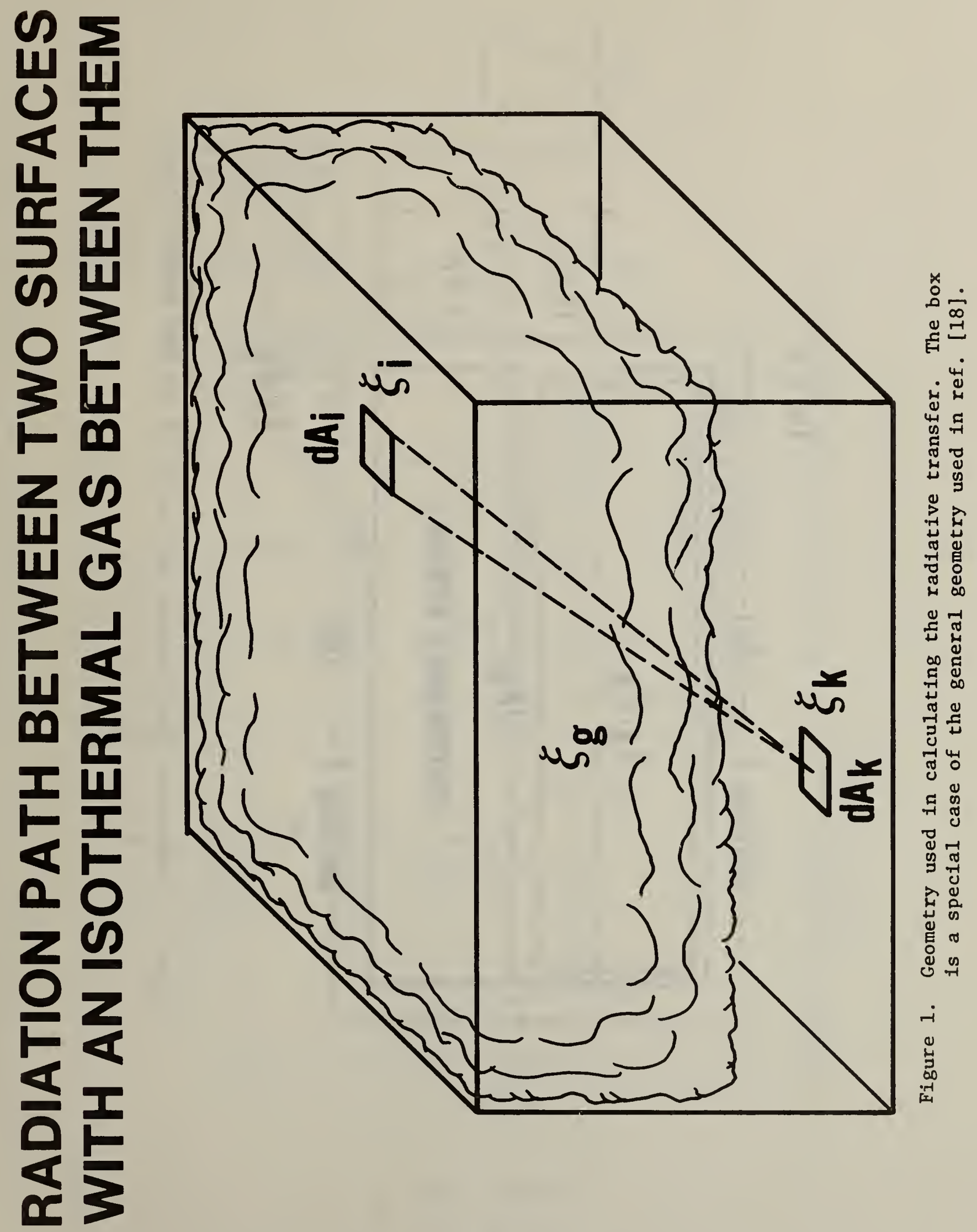




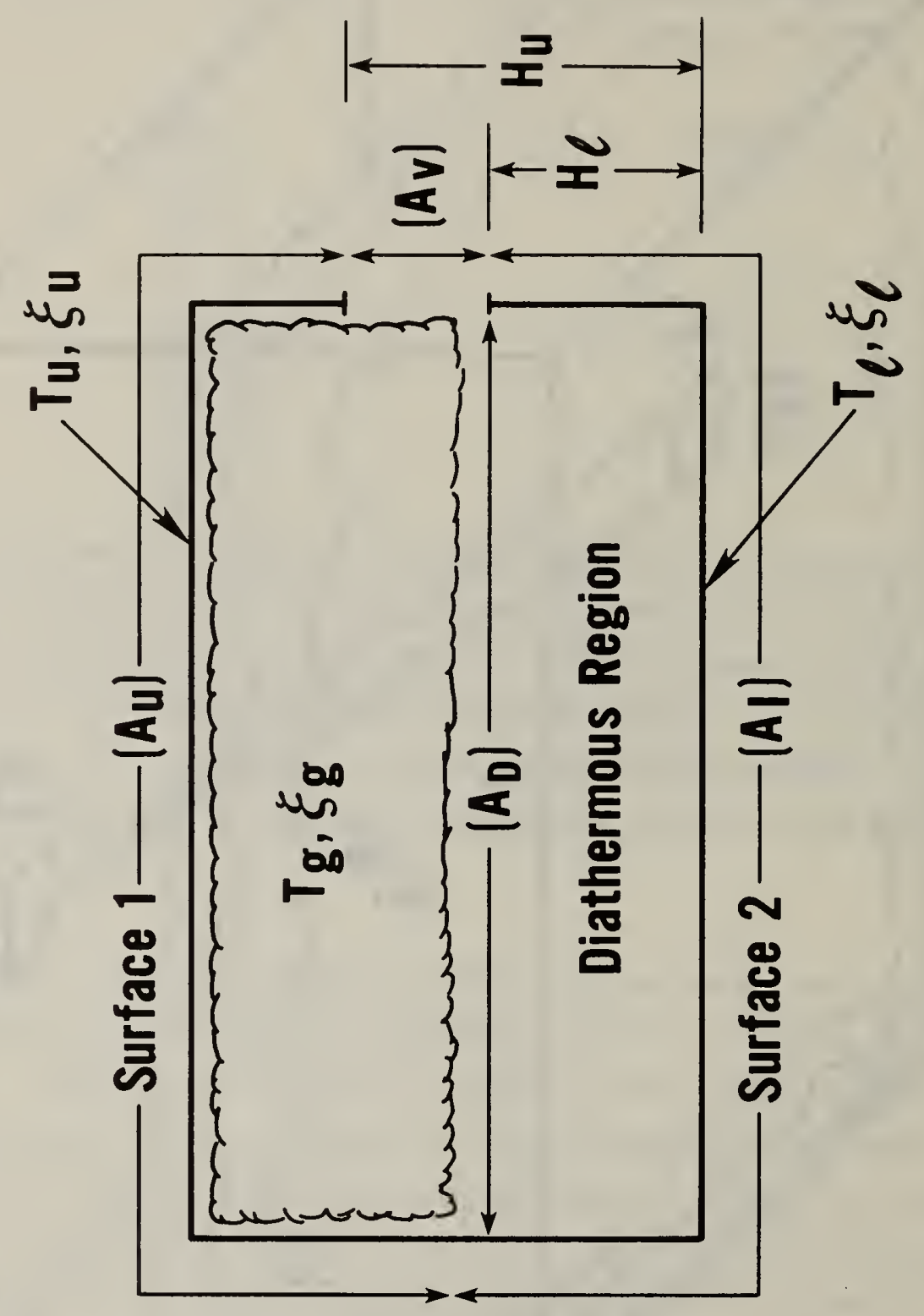

뭉

옹

岳

4

攵

त्न

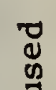

J

告

i

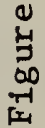




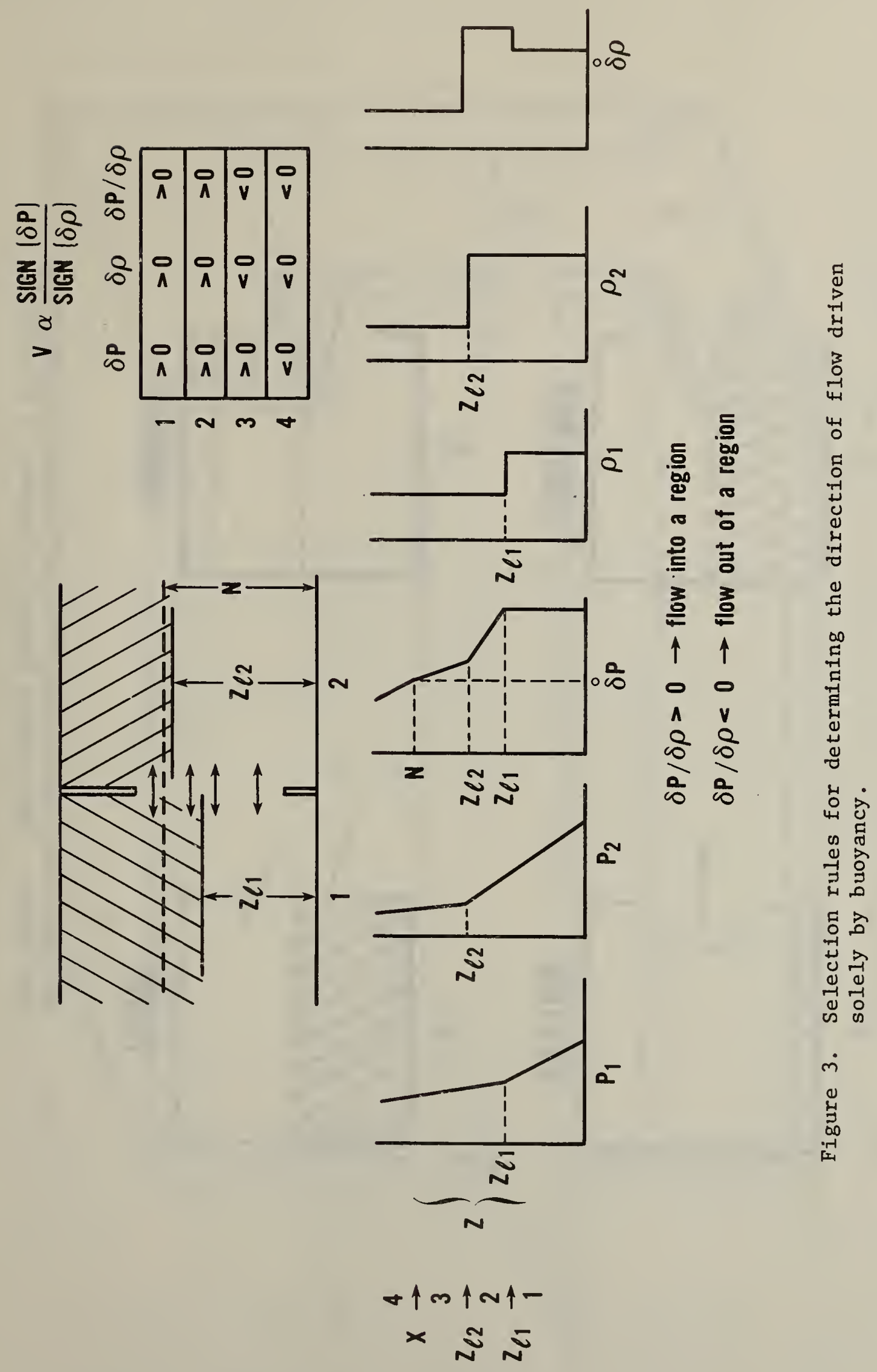



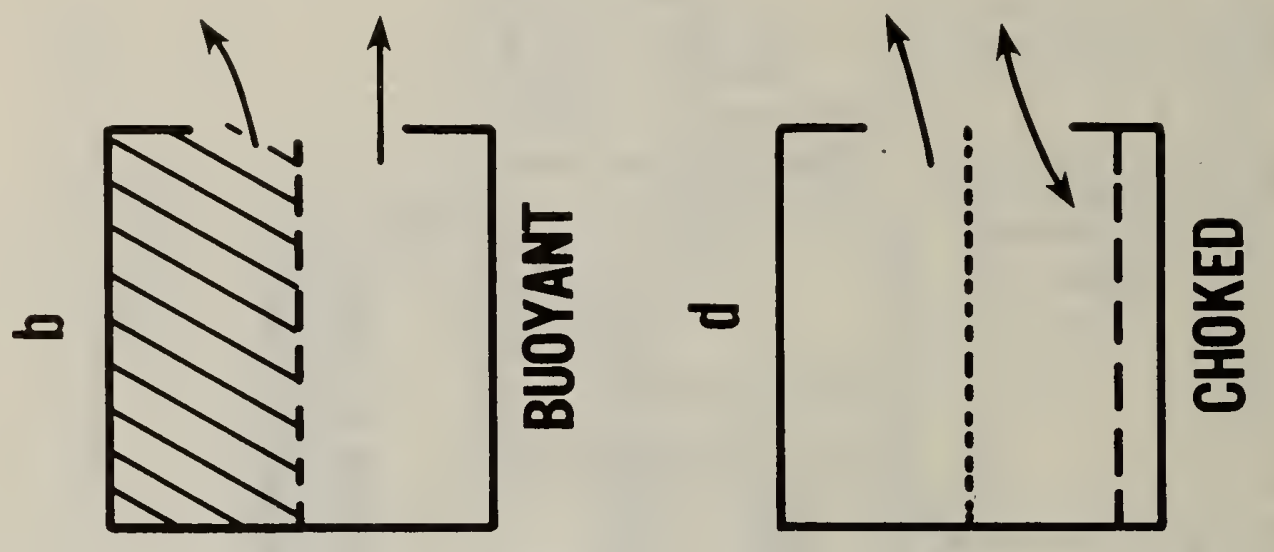

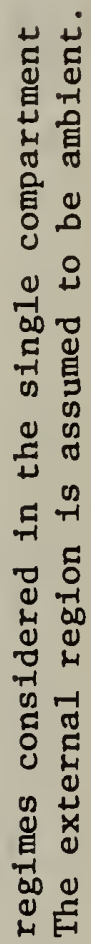
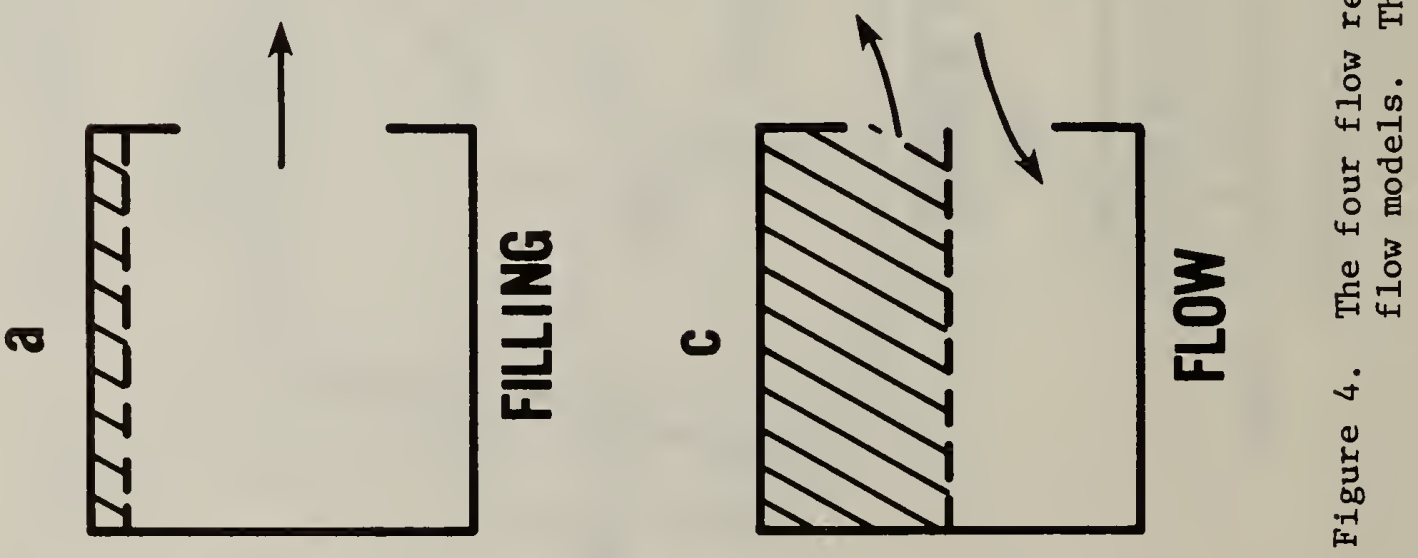


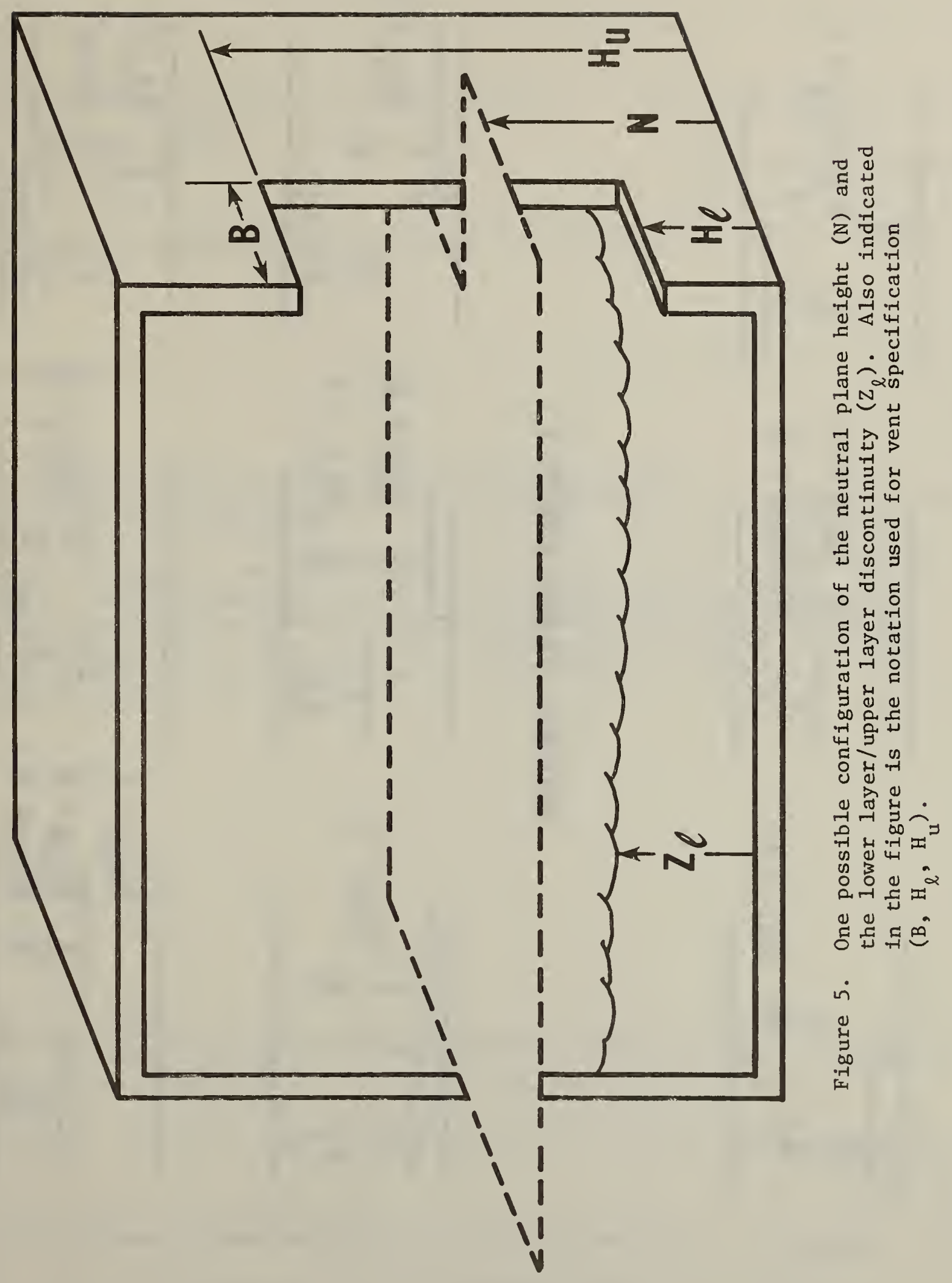




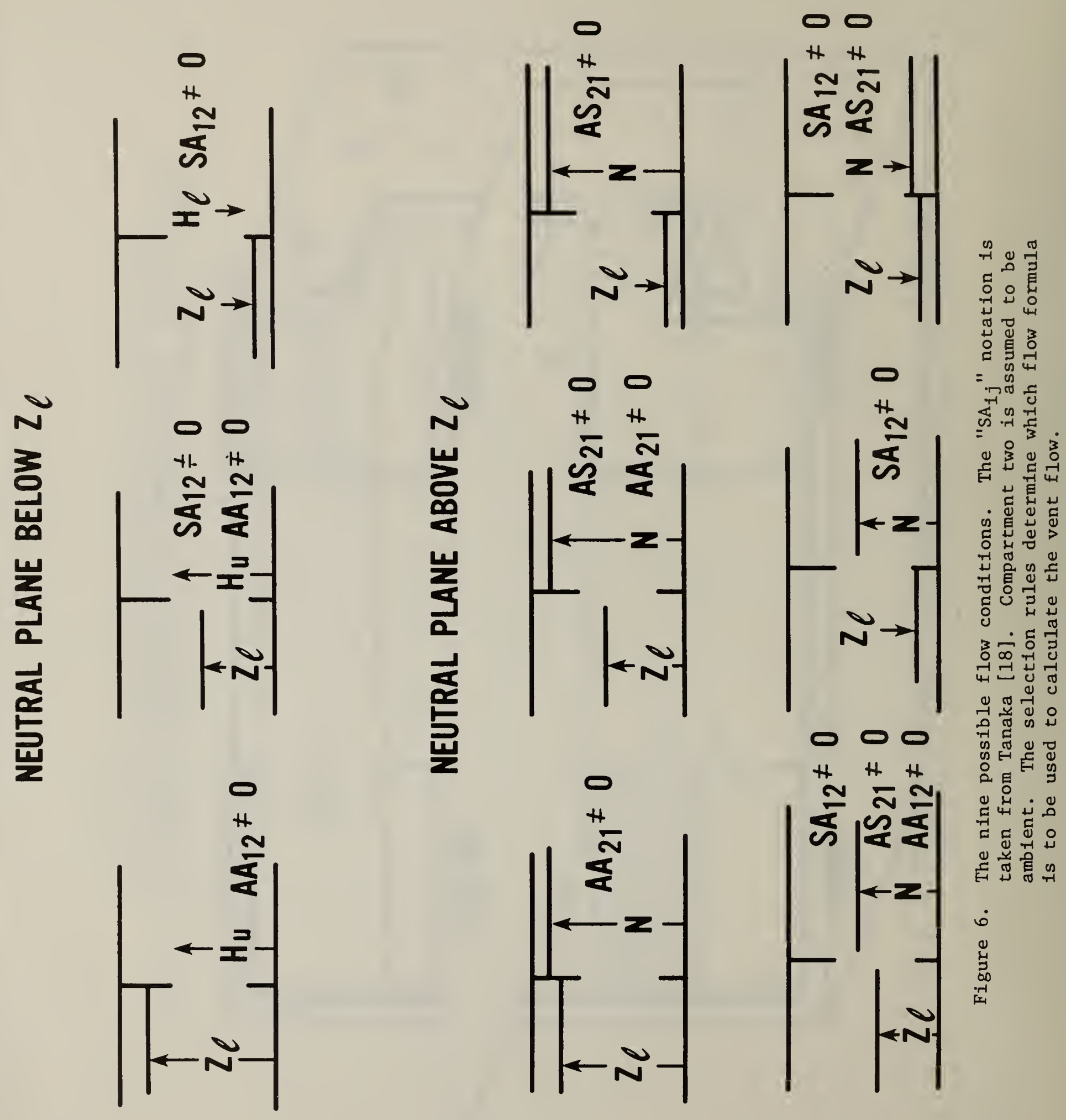


NBS-114A (REV. 2-8C)

U.S. DEPT. OF COMM

1. PUBLICATION OR REPORT NO.

BIBLIOGRAPHIC DATA

SHEET (See instructions)

NBSIR $83-2684$

2. Performing Organ. Report No

3. Publication Date

April 1983

4. TITLE AND SUBTITLE

A REVIEW OF COMPARTMENT FIRE MODELS

5. $A \cup T H O R(S)$

Walter $W$. Jones

\begin{tabular}{l|l}
. PERFORMING ORGANIZATION (If joint or other than NBS, see instructions) & 7. Contract/Grant No.
\end{tabular}

NATIONAL BUREAU OF STANDARDS

DEPARTMENT OF COMMERCE

WASHINGTON, D.C. 20234

8. Type of Report \& Period Covered

9. SPONSORING ORGANIZATION NAME AND COMPLETE ADDRESS (Street, City, State, ZIP)

10. SUPPLEMENTARY NOTES

Document describes a computer program; SF-185, FIPS Software Summary, is attached.

11. ABSTRACT (A 200-word or less factual summary of most significant information. If document includes a significant bibliography or literature survey, mention it here)

We have examined the concept of zone modeling as it has been applied to fire problems. The existing models which embody the zone concept are compared in order to ascertain the state-of-the-art in understanding of fire growth and fire spread processes. This review is intended to be a starting point for future modeling efforts and thus the discussion centers around the use of the various submodels.

12. KEY WORDS (Six to twelve entries; alphabetical order; capitalize only proper names; and separate key words by semicolons) compartment fires; fire models; room fires; smoke movement; zone models

13. AVAILABILITY

XI Unlimited

$\square$ For Official Distribution. Do Not Release to NTIS

$[$ Order From Superintendent of Documents, U.S. Government Printing Office, Washington, D.C. 20402.

X.] Order From National Technical Information Service (NTIS), Springfield, VA. 2216I
14. NO. OF

PRINTED PAGES

41

15. Price 



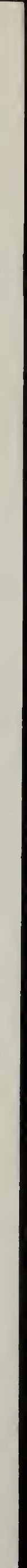


